\title{
Por que o Programa Minha Casa Minha Vida só poderia acontecer em um governo petista?
}

\author{
Why could the Minha Casa Minha Vida Program only have \\ happened in a government headed by the Labor Party?
}

Danielle Klintowitz

\begin{abstract}
Resumo
No período de gestão do Partido dos Trabalhadores (PT) no governo federal, configurou-se uma dupla agenda para a política habitacional: a primeira ligada à plataforma de reforma urbana, com previsão de descentralização e gestão participativa, e a segunda consubstanciada na premissa de reestruturação do setor imobiliário, estruturada em uma política exclusiva de provisão habitacional com promoção privada e financiamento público. Esse modelo de governança garantiu a distribuição de benefícios a ambas coalizões que representavam essas agendas, além de ter legitimado a política habitacional na agenda pública. No presente trabalho, analisou-se a trajetória do principal programa habitacional desenvolvido na época (MCMV), discutindo suas implicações para o direito à moradia e o papel dos atores do setor habitacional neste contexto.
\end{abstract}

Palavras-chave: política habitacional; reforma urbana; mercado imobiliário; Programa Minha Casa Minha Vida; coordenação de interesses.

\begin{abstract}
Since the Labor Party has been governing Brazil, there has been a double agenda for the housing policy: the first one is linked to the urban reform platform, with a forecast of decentralization and participatory management, and the second is embodied in the premise of restructuring of the real estate sector, structured in an exclusive housing policy with private promotion and public funding. This governance model has ensured the distribution of benefits to both coalitions representing these agendas, and has legitimized the housing policy within the public agenda. In this paper, we analyze the trajectory of the main housing program developed in this period (MCMV), discussing its implications to the right to housing and the role of actors in the housing sector within this context.
\end{abstract}

Keywords: housing policy; urban reform; real estate market; Minha Casa Minha Vida Program; coordination of interests. 


\section{Introdução}

Historicamente, a política habitacional brasileira agregou em torno de si muitos interesses públicos e privados. Durante o século XX, assistiu-se a uma forte articulação funcional no relacionamento entre Estado e setor produtivo, o que garantiu a priorização de políticas habitacionais mais voltadas ao crescimento econômico do que ao direito à moradia. Com a redemocratização e a desestruturação da política federal de habitação até então estruturada no Banco Nacional de Habitação (BNH), emergiram movimentos sociais urbanos, como o Movimento Nacional de Reforma Urbana (MNRU) - transformado posteriormente em Fórum Nacional da Reforma Urbana (FNRU) -, que conquistaram o estabelecimento de um progressista arcabouço jurídico para o desenvolvimento urbano e praticaram de forma participativa, junto com governos locais de esquerda, algumas experiências de implementação no território, constituindo uma nova matriz relacional com o Estado que ficou conhecida como o "modo petista de governar".

Com a ascensão ao governo federal do Partido dos Trabalhadores (PT) que teve desde sua fundação uma estreita relação com os ideários da reforma urbana, criaram-se amplas expectativas nos atores ligados a essa plataforma de que o novo momento representaria um marco de ruptura no legado histórico da política habitacional voltada ao desenvolvimento econômico e o início de um ciclo virtuoso de implementação do "modo petista de governar" na escala federal.
Ao tornar-se Presidente da República, Luiz Inácio Lula da Silva reconhecendo, de maneira inovadora, os movimentos de moradia como players do setor, conformou uma estratégia de coordenação de interesses ousada, colocando na mesa de negociação movimentos de moradia e setor produtivo, coalizões com interesses historicamente opostos.

Estruturou-se, apoiado nesse contexto, um programa habitacional - o Minha Casa Minha Vida (MCMV) - que ganhou status de política por seu vigor de recursos e apoio multifacetado conquistado. 0 desenho desse programa atendeu à necessidade de sustentação da reestruturação do setor produtivo da construção civil e mercado imobiliário, que estava em curso, com investimentos keynesianos que impactaram a sustentação macroeconômica do país, dialogando pouco com as necessidades habitacionais das cidades brasileiras e com o Sistema Nacional de Habitação de Interesse Social (SNHIS) que estava em construção desde 2005.

No entanto, apesar dos ganhos assimétricos conquistados pelos movimentos de moradia em relação à coalizão do setor produtivo e do enfraquecimento definitivo do SNHIS, a coordenação de interesses que se estabeleceu no MCMV tornou-se extremamente eficiente e se expandiu para além dos interesses dessas coalizões, sendo capaz de se ramificar em várias escalas de coordenação: entre o setor público e privado; entre os diferentes ministérios; entre União e municípios.

Esse arranjo que se estabeleceu então foi capaz de garantir que ambas as agendas concorrentes - de reforma urbana e do setor 
produtivo - convivessem de maneira articulada, mesmo que preservassem suas contradições. Criou-se um imbricamento cooperativo que permitiu construir uma política habitacional que se tornou uma das principais forças desse governo. ${ }^{1}$

Com o arranjo criado nesse ambiente, estabeleceu-se um "regime de política" (Couto e Abrucio, 2003) no qual se alcançou um entendimento quase hegemônico acerca da política habitacional com seu lastreamento em interesses objetivos dos atores envolvidos. Assim, neutralizaram-se possíveis conflitos dos atores e suas coalizões com Estado, imbricando e engendrando-os na defesa da própria política, mesmo que apenas parte dessa fosse conveniente para concretização de seus interesses e que apenas parte de seus interesses fosse efetivamente atendida.

Neste artigo, busca-se discutir como se deu essa coordenação de interesses na construção e implementação do Programa Minha Casa Minha Vida e quais os rumos que a política habitacional nacional tomou a partir dessa nova configuração.

\section{MCMV: entre o direito à moradia e reestruturação do setor produtivo}

No contexto de euforia do mercado imobiliário com o aumento dos recursos disponíveis e com a reforma institucional que garantia a segurança dos negócios e lançamentos grandiosos, a crise internacional do subprime de 2008 ameaçou a possibilidade de venda dos empreendimentos em construção, impondo ainda sérias dificuldades financeiras às grandes empresas que naquele momento detinham grande soma de investimentos imobilizados em bancos de terra.

Nesse cenário, a conjuntura econômica foi o pretexto determinante para ampliação dos mecanismos e volume de recursos destinados ao setor habitacional. Através do MCMV, com o objetivo explícito de socorrer o setor produtivo da construção civil e mercado imobiliário e evitar o aprofundamento da crise do mercado, o governo federal colocou o problema da habitação definitivamente nos termos propostos pelo setor imobiliário. Segundo dados do Ministério do Planejamento (Brasil, 2014), entre 2009 e 2014 foram investidos $\mathrm{R} \$ 251,8$ bilhões no MCMV, considerando os subsídios diretos e linhas de crédito disponibilizadas. Esses recursos foram responsáveis pela contratação de 3,75 milhões de unidades habitacionais em todo o Brasil.

O MCMV foi elaborado pela Casa Civil e pelo Ministério da Fazenda, em diálogo direto com os setores imobiliários e da construção, desconsiderando diversos avanços institucionais na área de desenvolvimento urbano, bem como a interlocução com o restante da sociedade civil. 0 Ministério das Cidades (MCidades) que tinha na sua origem um forte imbricamento com os atores ligados à plataforma da reforma urbana foi posto de lado na concepção inicial, sendo chamado a contribuir apenas depois de elaborada a macroestrutura de funcionamento do Programa.

Inicialmente pensava-se em uma estratégia destinada apenas às famílias de estratos médios - com renda acima de três salários mínimos (SM) - com possibilidade de acesso a financiamentos e que necessitavam um 
percentual menor de subsídio atrelado a eles. Como se tratava de um programa destinado a reduzir as perdas financeiras do setor produtivo, os empresários do setor não queriam correr riscos. No entanto, o MCidades lutou pela entrada das famílias de menor renda no programa, o que implicava maiores subsídios públicos. Os subsídios são fundamentais para o acesso das famílias de baixa renda ao mercado habitacional e, ao mesmo tempo, trazem vantagens também ao setor produtivo que tem o mercado habitacional ampliado com famílias que de outra maneira estariam fora.

0 Presidente Lula, orientado pela busca de soluções de arbitragem que caracterizou seu governo (Singer, 2012), viu aí uma possibilidade também de ganho de capital político junto à base de menor renda, além da ampliação do mercado habitacional fundamental para as empresas do setor. Assim, criou-se um programa com um patamar histórico de subsídios para as famílias com renda de até três SM.

No entanto, o modelo do MCMV implementado privilegiou a concessão maciça de subsídios para faixas de renda mais altas (Faixa 2) que poderiam adquirir financiamentos maiores com menores percentuais de subsídio. Ao mesmo tempo, também se elevou a faixa de renda financiada pelo Fundo de Garantia sobre o Trabalho (FGTS), com melhores condições de juros, e parte dessa demanda poderia ser atendida pelo Sistema Brasileiro de Popança e Empréstimo (SBPE), ${ }^{2}$ liberando recursos do FGTS com financiamento mais barato para famílias de menor renda (Bonduki, 2014). Assim, apesar dos expressivos subsídios concebidos de maneira inédita no país para as faixas de renda mais baixas, o Programa ainda reproduz as antigas lógicas das políticas habitacionais, em que 0 atendimento não é distribuído de acordo com as necessidades reais, mas de acordo com os interesses dos formuladores e implementadores.

As metas do programa por faixa de atendimento pouco dialogam com o déficit habitacional acumulado por faixa de renda no país. Na primeira fase do Programa (MCMV1), enquanto $91 \%$ do déficit estava concentrado na faixa 1 (renda até três SM), apenas 40\% das unidades produzidas destinaram-se a esse público. Como consequência, apenas $6 \%$ do déficit habitacional das famílias com menor renda foi atingindo, ${ }^{3}$ enquanto $93 \%$ e $95 \%$ do déficit das faixas de renda mais altas (2 e 3) foram atendidos, respectivamente. Na segunda etapa (MCMV2), embora a meta para a faixa 1 tenha sido expressivamente ampliada em detrimento das demais faixas, o combate ao déficit dessas famílias ainda é percentualmente muito inferior ao atendimento às famílias com maior renda.

No modelo institucional desenhado para o MCMV, a análise de projetos, bem como a contratação de obras e medição de etapas finalizadas é parte dos procedimentos de responsabilidade da Caixa Econômica Federal (CEF), não cabendo aos municípios responsabilidade formal pelos resultados alcançados. Nesse modelo, o promotor do empreendimento passa a ser o setor privado, o poder público assume um papel apenas de financiador e organizador da demanda. Cabe ao mercado privado a promoção dos empreendimentos habitacionais elaborados de acordo com as exigências técnicas mínimas do MCMV, principalmente no que se refere ao cálculo do valor da unidade habitacional, de forma a se enquadrar no perfil financiado e, ao mesmo tempo, garantir maior taxa 
Tabela 1 - Metas do MCMV e déficit habitacional acumulado por faixas de renda

\begin{tabular}{|c|c|c|c|c|c|}
\hline \multicolumn{6}{|c|}{ MCMV 1} \\
\hline Faixas de renda* & $\begin{array}{c}\text { Déficit } \\
\text { acumulado } \\
\text { (em \%) }\end{array}$ & $\begin{array}{c}\text { Metas } \\
\text { do MCMV } 1 \\
(\mathrm{em} \%)\end{array}$ & $\begin{array}{l}\text { Déficit } \\
\text { acumulado** } \\
\text { (em mil) }\end{array}$ & $\begin{array}{c}\text { Metas } \\
\text { do MCMV1 } \\
\text { (em mil) }\end{array}$ & $\begin{array}{l}\text { \% Déficit } \\
\text { acumulado } \\
\text { atendido }\end{array}$ \\
\hline Faixa 1 & 91 & 40 & 6.550 & 400 & 6 \\
\hline Faixa 2 & 6 & 40 & 430 & 400 & 93 \\
\hline Faixa 3 & 3 & 20 & 210 & 200 & 95 \\
\hline Total & 100 & 100 & 7.190 & 1.000 & 14 \\
\hline \multicolumn{6}{|c|}{ MCMV 2} \\
\hline Faixas de renda & $\begin{array}{c}\text { Déficit } \\
\text { acumulado } \\
\text { (em \%) }\end{array}$ & $\begin{array}{c}\text { Metas } \\
\text { do MCMV } 2 \\
(\mathrm{em} \%)\end{array}$ & $\begin{array}{l}\text { Déficit } \\
\text { acumulado*** } \\
\text { (em mil) }\end{array}$ & $\begin{array}{c}\text { Metas } \\
\text { do MCMV2 } \\
\text { (em mil) }\end{array}$ & $\begin{array}{l}\% \text { Déficit } \\
\text { acumulado } \\
\text { atendido }\end{array}$ \\
\hline Faixa 1 & 72 & 60 & $4.698,76$ & 1.440 & 31 \\
\hline Faixa 2 & 15 & 30 & 941,05 & 720 & 77 \\
\hline Faixa 3 & 13 & 10 & 850,19 & 240 & 28 \\
\hline Total & 100 & 100 & 6.490 & 2.400 & 37 \\
\hline
\end{tabular}

* As faixas de renda do Programa MCMV não são as mesmas faixas estabelecidas pela metodologia da Fundação João Pinheiro (FJP) para coleta dos dados. Enquanto o MCMV trabalha com a faixa 2 para famílias com rendimento entre 3 e 6 SM, a FJP faz o cálculo do déficit para famílias com rendimento entre 3 e 5 SM. Optou-se por estabelecer esta relação como proxy, já que estas são as únicas informações disponíveis. No entanto, as análises precisam considerar esta pequena distorção.

** com base no déficit habitacional 2000 (FJP, 2004).

*** com base no déficit habitacional 2010 (FJP, 2013).

Fonte: Elaboração própria. FJP (2004 e 2013) e CEF (2013).

de lucro possível em seus projetos. Nesse contexto, apesar do histórico patamar de recursos orçamentários destinados a subsídios para atender a população de mais baixa renda no MCMV, os empreendimentos para essa faixa de renda são fortemente marcados por uma lógica de produção do mercado imobiliário privado, o que nem sempre dialoga com as necessidades relacionadas ao direto à moradia.

Apesar de existirem outras modalidades, como o Programa Nacional de Habitação Rural (PNHR), Minha Casa Minha Vida Entidades (MCMV-E), o Sub-50, destinado a municípios com menos de 50 mil habitantes e uma modalidade para urbanização, analisando-se os montantes alocados nos diferentes fundos e as unidades contratadas, observa-se que o núcleo central do MCMV, desde o início, foi aquele voltado para as empresas que acessam diretamente os recursos do FAR ou do FGTS, ${ }^{4}$ modalidades com protagonismo do mercado privado (Brasil, 2014).

Nestas modalidades do MCMV destinadas a empresas (FAR - faixa 1, FGTS - faixa 2 e FGTS - faixa 3), o fluxo de contratação e produção desenhado garantem o protagonismo direto das empreendedoras. A operacionalização se dá mediante o repasse de recursos do governo federal para construtoras, que, por sua vez, constroem os empreendimentos habitacionais. Mesmo na modalidade faixa 1, que conta com expressivos subsídios, a produção se dá por oferta privada ao poder público, isto é, a construtora define a cidade onde pretende fazer o empreendimento, o terreno, o projeto e o número de unidades; aprova junto aos órgãos 


\section{Gráfico 1 - Contratações \\ do MCMV 1 e 2 nas diferentes modalidades (\%)}

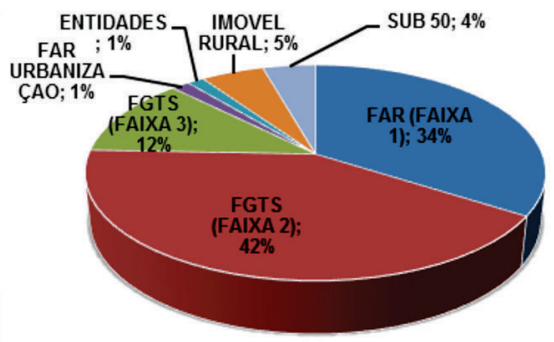

Fonte: Brasil, Balanço PAC 2 - 4 anos de execução. Dez 2014.

competentes e vende integralmente o que produzir para a CEF, sem gastos de incorporação imobiliária e comercialização e sem riscos de inadimplência dos compradores.

\section{A implementação do MCMV, o enfraquecimento do SNHIS e a desarticulação aos processos de planejamento urbano e habitacional}

Com esse desenho adotado para o programa, fortemente ancorado na promoção das habitações pelo setor privado, o MCMV entrou em choque com os princípios do SNHIS que era pautado pelo papel estratégico do setor público e pela descentralização federativa, ignorando em larga medida premissas e debates acumulados em torno do Plano Nacional de Habitação de Interesse Social (PlanHab) (Krause, Balbim e Lima Neto, 2013; Cardoso, Aragão e Araujo, 2011).

\section{Gráfico 2 - Contratações do MCMV \\ nas modalidades destinadas \\ a empresas e outros (\%)}

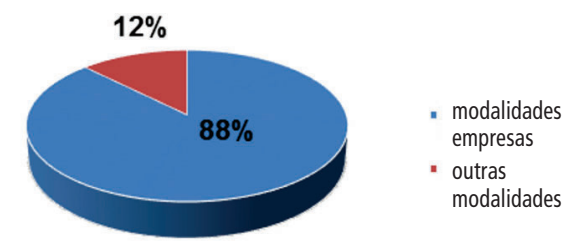

Fonte: Brasil, Balanço PAC 2 - 4 anos de execução. Dez 2014.

Um dos impactos mais imediatos sobre os programas desenvolvidos no âmbito do Fundo Nacional de Habitação de Interesse Social (FNHIS) diz respeito à eliminação dos repasses de recursos para as ações de provisão habitacional para municípios e cooperativas habitacionais, o que implicou a realização integral da provisão habitacional nos termos das modalidades previstas pelo MCMV, e o FNHIS não pôde mais ter programas alternativos para essa modalidade. Vale destacar ainda que, a partir de 2010, priorizou-se a alocação de recursos desse fundo em obras complementares a projetos em andamento financiados com recursos do PAC, que inclui o MCMV, o que mostra um caráter subsidiário do FNHIS nas decisões de política habitacional (Cardoso, Aragão, Araújo, 2011; Relatório de Gestão do Conselho Gestor do FNHIS, 2013).

Outra importante implicação para o FNHIS foi o esvaziamento de recursos desse fundo. Entre os anos de 2003 e 2010, revertendo definitivamente a estagnação presente 
Tabela 2 - Recursos orçamentários executados do FNHIS,

PAC e PMCMV (2006-2014)

\begin{tabular}{c|c|c|c|c|c|c|c}
\hline \multirow{2}{*}{ Ano } & \multicolumn{2}{|c|}{ FNHIS } & \multicolumn{2}{c|}{ PAC Favelas } & \multicolumn{2}{c}{ MCMV } & \multicolumn{2}{c}{ Total } \\
\cline { 2 - 8 } & Bilhões de R\$ & $\%$ & Bilhões de R\$ & $\%$ & Bilhões de R\$ & $\%$ & Bilhões de R\$ \\
\hline 2006 & 1 & 40 & 1,52 & 60 & - & - & 3,52 \\
2007 & 0,3 & 13 & 1,97 & 87 & - & - & 3,27 \\
2008 & 0,8 & 23 & 2,7 & 77 & - & - & 4,5 \\
2009 & 1,01 & 10 & 3,88 & 38 & 5,25 & 52 & 10,62 \\
2010 & 0,17 & 2 & 1,88 & 22 & 6,68 & 77 & 8,96 \\
2011 & 0,51 & 4 & 2,15 & 16 & 10,98 & 80 & 13,84 \\
2012 & 0,13 & $\mathbf{1}$ & 3,2 & 20 & 12,55 & 79 & 16,09 \\
2013 & 0,21 & $\mathbf{1}$ & 3,65 & 19 & 15,63 & 80 & 19,68 \\
2014 & 0,05 & $\mathbf{0 , 2}$ & 2,7 & 14 & 16,8 & 86 & 19,69 \\
\hline
\end{tabular}

Fonte: Elaboração própria. SIGA Brasil - Acompanhamento da execução orçamentária da União, entre 2006 e 2014.

no setor habitacional desde a extinção do BNH em 1986, o investimento federal, incluindo os investimentos com recursos onerosos do SBPE e do FGTS, saltou de R\$7,9 bilhões, em 2003, para R \$101,5 bilhões em 2010 (Brasil, 2014). No PPA de 2012 a 2015, dos 26\% dos recursos do Orçamento Geral da União (OGU) alocados para infraestrutura, 32,6\% foram destinados à habitação, o que equivale ao montante de $\mathrm{R} \$ 389,7$ bilhões dedicados ao setor em quatro anos de planejamento orçamentário. Entretanto, quando se observam os dados referentes à alocação de recursos, percebe-se claramente que o FNHIS foi desprivilegiado, apresentando um significativo declínio a partir 2010, quando se iniciam as contratações do MCMV.

Os recursos crescentes para o setor habitacional são alocados em outros fundings a fim de financiar programas habitacionais - PAC Favelas e Minha Casa Minha Vida (MCMV) - que não integram o modelo desenhado para o funcionamento do SNHIS. É importante ressaltar, também, que os recursos destinados ao FNHIS não só são menores em termos absolutos em relação aos outros fundings nesse período, como percentualmente sua participação nos recursos destinados à habitação perde importância, chegando a menos de $1 \%$ dos recursos totais orçamentários no final do período estudado.

Com quase a integralidade dos recursos, desenhou-se um programa - o MCMV - que acabou se transformando de maneira hegemônica no eixo central da política habitacional no Brasil, fixando sua atuação apenas na produção de novas moradias, atendendo plenamente aos interesses do mercado imobiliário e da construção civil, mas relegando ao esquecimento outras modalidades de enfrentamento às diferentes necessidades habitacionais. 
0 próprio PAC Favelas, ${ }^{5}$ que priorizava a modalidade de urbanização, acabou sendo prejudicado em detrimento do MCMV. O PAC tem um arranjo institucional em que os governos locais são promotores das intervenções, tornando o processo mais lento sem propiciar a celeridade no retorno do capital político e financeiro empregado pelo mercado imobiliário. Como afirma Fix (2011), a temporalidade político-eleitoral do MCMV parece se ajustar melhor ao ritmo do capital financeiro - que promete atropelar resistências de todos os tipos - do que àquele das lutas urbanas e dos direitos sociais que a urbanização representa.

A desarticulação da estrutura do MCMV aos processos municipais de planejamento urbano e habitacional suscitou o abandono desses processos de planejamento e desenvolvimento institucional que estavam em curso nas esferas subnacionais. 0 governo federal retirou a capacidade financeira, e consequentemente decisória e de atuação do SNHIS, em detrimento da alocação dos recursos em outro modelo, e, em consequência, os municípios também se desmobilizaram no atendimento às regras desse Sistema e direcionaram suas energias para a obtenção do maior número possível de unidades habitacionais por meio do MCMV (Rolnik, Klintowitz e lacovini, 2014).

A Lei $n^{0} 11.977 / 2009$ que dispõe sobre 0 MCMV, define como um dos critérios de priorização dos municípios, além da desoneração fiscal e doação de terrenos em áreas consolidadas, a implementação de instrumentos do Estatuto das Cidades. No entanto, essas regras de priorização nunca foram cumpridas. Segundo os entrevistados da CEF (Klintowitz, 2015), as contratações do Programa não adotam essas normativas de priorização porque dependem da disposição do mercado privado em apresentar projetos nas cidades onde o negócio é mais atrativo; e como a meta estabelecida de contratação de unidades era muito alta $(3,75 \mathrm{mi}-$ Ihões somando as fases 1 e 2 do MCMV), não existiu até o fim da segunda fase do Programa espaço para priorizar os municípios que haviam cumprido essas disposições legais. As contratações obedeceram apenas a disposição de lucro do mercado e as análises de viabilidade da CEF.

\section{0 impacto MCMV sobre o direito à cidade}

No entanto, na literatura sobre o tema ainda resta a dúvida se os municípios que tinham processos de planejamento estabelecidos tiveram vantagens em relação às contrações de unidades no MCMV. Para verificar a existência da correlação entre a existência dos instrumentos de planejamento que estavam sendo fomentados pelo MCidades e a contratação do MCMV realizou-se uma regressão linear com os dados de contratação disponíveis (Klintowitz, 2015). ${ }^{6}$ Além de verificar a correlação entre instrumentos de planejamento e o número de unidades contratadas no âmbito do MCMV nos municípios brasileiros, nessa regressão buscava-se inferir o que explica o "sucesso" da contratação do Programa nos diferentes municípios brasileiros, já que os dados mostram que alguns municípios extrapolaram o atendimento de suas metas, enquanto outros não conseguiram contratar nem a metade da meta estipulada.

Para verificar o sucesso das contratações em alguns municípios, coletou-se variáveis que poderiam explicar maiores contratações de 
unidades habitacionais no MCMV em alguns municípios em detrimento de outros. Para avaliar a contração em cada município brasileiro foi utilizado um banco de dados fornecido pela CEF. Esse banco de dados continha informações sobre todas as unidades habitacionais contratadas na primeira fase do MCMV que finalizou com 1 milhão de unidades em maio de 2011. Como variável dependente elaborou-se um "índice de sucesso de contratações" que foi calculado a partir da divisão do número de unidades contratadas pela meta estabelecida pelo governo federal - em número de unidades. Como as metas de contratação do MCMV são estipuladas a partir do déficit habitacional, essa variável relaciona as necessidades habitacionais representadas pelos déficits dos municípios com o número de unidades contratadas.

Inicialmente constatou-se que as contratações da modalidade faixa 1 do MCMV não apresentavam relação direta com os números do déficit habitacional de cada município. Existe uma grande diversidade de situações nas relações entre o número de unidades contratadas no âmbito do MCMV1 e o déficit de cada município. Uma parte significativa de municípios acima de 20 mil habitantes (29\%) não tem nenhuma unidade contratada apesar de terem metas estabelecidas pelo Governo Federal; $40 \%$ dos municípios tiveram um range de unidades contratadas entre 10 e $50 \%$ em relação ao seu déficit, enquanto $6 \%$ dos municípios têm mais unidades contratadas do que o número do déficit habitacional calculado.

Os resultados em relação ao "índice de sucesso", por sua vez, também indicaram que não existe nenhuma correlação entre a adesão dos municípios ao SNHIS, sua regularidade e implementação dos itens exigidos pelo Sistema (conselho, fundo e plano) com o número de contratações. Da mesma forma, a existência de instrumentos urbanísticos de planejamento e gestão do solo, não apresentam correlações com o sucesso de contratações do MCMV.

Apenas as variáveis do bloco de análise relacionado às dimensões territoriais demonstraram correlações. Essas variáveis apresentaram uma correlação positiva entre as tipologias de cidades identificadas como "periferia dos polos regionais" e "grandes cidades isoladas" e o sucesso de contratação de unidades do MCMV1 na Faixa 1, demonstrando que nesses tipos de cidades se realizam percentualmente mais contratações do MCMV em relação a seu déficit habitacional. Uma explicação para essa correlação está relacionada ao mercado de terras desses municípios. Essas tipologias de cidades apresentam menor dinâmica imobiliária, com menor disputa pela terra, em relação a outras tipologias que não mostraram correlações com o sucesso de contratação das unidades do MCMV. A baixa dinâmica de terras poderia então ser uma explicação para o maior número de contratações, pois, os promotores privados do MCMV escolhem com total liberdade as cidades onde querem produzir empreendimentos e, segundo entrevistas (Klintowitz, 2015), o preço dos terrenos tem se apresentado como uma das principais variáveis para esta escolha.

Em relação ao porte populacional, observa-se também uma correlação positiva entre 0 sucesso de contratação e as faixas populacionais entre 50 mil e 500 mil habitantes, demonstrando que o programa tem dificuldades em "rodar" nas cidades maiores, onde novamente o mercado de solo é mais dinâmico e a terra para produção de habitação de interesse social torna-se mais escassa e cara. 
0 resultado demonstrou, então, que existem fortes indícios de que a variável explicativa mais forte para o sucesso de contratação das unidades do MCMV é realmente o preço da terra. As variáveis relacionadas à institucionalização do setor habitacional, que teve grande fomento nos primeiros anos do MCidades, assim como o investimento na implementação de instrumentos de planejamento e gestão do solo urbano do Estatuto da Cidade, não tiveram significância na contratação desse programa.

Fica evidente que o modelo implementado pelo MCMV dialoga com as lógicas do mercado imobiliário, mas não com as lógicas da política habitacional defendida pela plataforma da reforma urbana e pelo próprio MCidades em seus primeiros anos, já que a definição de onde haverá maior número de unidades são determinadas pelas facilidades e perspectivas de maiores ganhos dos produtores privados e não pela existência de necessidades habitacionais, planejamento e priorizações da gestão pública.
Como as gerências regionais da CEF (Gidur) têm metas de contratação, tem-se assistido, ainda, distorções entre as necessidades habitacionais existentes nos municípios e a contratação de unidades residenciais no âmbito do MCVM orquestradas pela própria CEF e seus gerentes que têm usado diferentes artifícios para alcançar as metas exigidas (Klintowitz, 2015). Com a anuência da CEF e do MCidades, os municípios menores, onde o preço da terra urbanizada é menor, estão conseguindo obter mais unidades do MCMV.

Em consequência desses fatores, apesar de as capitais dos estados brasileiros concentrarem $37,5 \%$ do déficit habitacional, 0 desempenho proporcional apresentado nesses municípios para os imóveis da faixa 1 na fase 1 do Programa é muito reduzido (24\%) em comparação com os outros recortes territoriais (76\%).

Confirmando os dados obtidos na regressão linear apresentada, Lima Neto, Krause

Tabela 3 - Contratações para municípios acima de 50 mil habitantes (MCMV 1, faixa 1)

\begin{tabular}{|c|c|c|c|c|c|c|}
\hline $\begin{array}{l}\text { Recorte } \\
\text { territorial }\end{array}$ & $\begin{array}{c}\text { Déficit urbano } \\
\text { - Faixa } 1\end{array}$ & $\begin{array}{c}\text { Unidades } \\
\text { contratadas } \\
\text { - famílias até } \\
\text { R\$1.600 (OGU) }\end{array}$ & $\begin{array}{c}\text { Unidades } \\
\text { contratadas } \\
\text { - famílias até } \\
\text { R\$1.600 (FGTS) }\end{array}$ & \multicolumn{2}{|c|}{$\begin{array}{l}\text { Total unidades } \\
\text { contratadas }\end{array}$} & $\begin{array}{l}\text { Desempenho } \\
\text { contratação }\end{array}$ \\
\hline $\begin{array}{l}>100 \text { mil } \\
\text { habitantes }\end{array}$ & 826.963 & 272.363 & 56.518 & 328.881 & 33 & 40 \\
\hline $\begin{array}{l}50 \text { a } 100 \text { mil } \\
\text { habitantes }\end{array}$ & 504.594 & 159.278 & 21.866 & 181.144 & 18 & 36 \\
\hline Capitais estaduais & 1.238 .247 & 204.221 & 32.364 & 236.585 & 24 & 19 \\
\hline $\begin{array}{l}\text { RM de capitais } \\
\text { estaduais (sem a } \\
\text { capital) }\end{array}$ & 725.090 & 179.459 & 78.268 & 257.727 & 26 & 36 \\
\hline
\end{tabular}

Fonte: Ministério das Cidades (2014). 
e Furtado (2015), em estudo que busca desvendar as correlações entre a produção dos empreendimentos do MCMV na faixa 1 e o déficit habitacional, na dimensão intrametropolitana, revelaram que a maior produção habitacional em municípios nas metrópoles estudadas se dá nos municípios mais periféricos e com menor participação na atividade econômica metropolitana. Os autores demonstram, ainda, que a média da distância dos empreendimentos ao centro de cada RM aumentou no MCMV2, o que nos permite supor que o efeito de valorização imobiliária, decorrida do próprio MCMV1, já apresenta impactos para a própria produção dos novos empreendimentos do Programa. A partir de seus estudos sobre as correlações entre a produção dos empreendimentos e sua localização, os autores ainda afirmam que a ênfase do MCMV1 e 2 foi de produção de casas, e o quesito de localização e inserção na cidade resultado das forças e interesses conhecidos e presentes na ordenação típica do urbano e não fez parte da formulação programática do MCMV.

A identificação das necessidades habitacionais representada exclusivamente pelo déficit habitacional, incorporado ao modelo de política habitacional produzido pelo MCMV, traz resultados muito diversos dos sentidos do "direito à cidade" defendidos pela plataforma da reforma urbana, como se observa na série de estudos de caso que tem sido realizados a respeito da implementação do MCMV nas cidades brasileiras.

Tabela 4 - Avaliação dos Moradores do MCMV 1, faixa 1, sobre o atendimento por serviços na moradia atual, em comparação com à moradia anterior (em \%)

\begin{tabular}{|c|c|c|c|c|c|}
\hline & Características avaliadas & Melhorou & Piorou & Ficou igual & Não respondeu \\
\hline $\begin{array}{c}\text { Acesso } \\
\text { à infraestrutura } \\
\text { básica }\end{array}$ & $\begin{array}{l}\text { Rede de esgoto } \\
\text { Pavimentação } \\
\text { Coleta de lixo } \\
\text { Iluminação pública } \\
\text { Fornecimento de energia elétrica } \\
\text { Fornecimento de água encanada } \\
\text { Acesso aos veículos } \\
\text { Calçadas }\end{array}$ & $\begin{array}{l}49,7 \\
47,4 \\
40,2 \\
38,0 \\
35,4 \\
32,8 \\
34,8 \\
36,7\end{array}$ & $\begin{array}{r}8,4 \\
15,2 \\
11,3 \\
19,1 \\
7,2 \\
20,0 \\
23,2 \\
28,5\end{array}$ & $\begin{array}{l}41,5 \\
36,5 \\
47,8 \\
42,2 \\
57,0 \\
46,9 \\
39,5 \\
34,0\end{array}$ & $\begin{array}{l}0,4 \\
1,0 \\
0,6 \\
0,8 \\
0,4 \\
0,3 \\
2,5 \\
0,9\end{array}$ \\
\hline $\begin{array}{l}\text { Acesso } \\
\text { à cidade }\end{array}$ & $\begin{array}{l}\text { Acesso a comércio } \\
\text { Acesso a equipamentos e serviços públicos } \\
\text { Policiamento } \\
\text { Transporte público } \\
\text { Acesso ao trabalho } \\
\text { Acesso à escola } \\
\text { Correios }\end{array}$ & $\begin{array}{l}21,3 \\
20,1 \\
26,8 \\
30,2 \\
20,5 \\
26,9 \\
22,3\end{array}$ & $\begin{array}{l}61,2 \\
44,0 \\
39,9 \\
38,7 \\
44,7 \\
35,9 \\
33,7\end{array}$ & $\begin{array}{l}17,1 \\
33,5 \\
31,5 \\
30,0 \\
29,4 \\
27,7 \\
42,9\end{array}$ & $\begin{array}{l}0,5 \\
2,4 \\
1,8 \\
1,1 \\
5,4 \\
9,5 \\
1,2\end{array}$ \\
\hline
\end{tabular}

Fonte: Elaboração própria. Pesquisa Rede Moradia Cidade (2014). Chamada MCTI/CNPq/MCIDADES n 11/2012. 
A pesquisa realizada pela Rede Moradia Cidade, 2014, ${ }^{7}$ por exemplo, revelou que a localização das novas moradias produzidas no âmbito do MCMV tem importantes impactos nos beneficiários em relação ao acesso a serviços e equipamentos públicos. Apesar de no Estado de São Paulo $43 \%$ das famílias pesquisadas terem vindo de assentamentos precários e $56 \%$ de áreas de risco, enquanto 0 acesso aos serviços básicos de infraestrutura melhorou em relação à moradia anterior, as características classificadas como de acesso à cidade (acesso ao comércio, ao trabalho, a equipamentos e serviços públicos; policiamento, transporte público, à escola e aos correios) apresentaram significativa piora em relação à moradia anterior.

\section{A tríplice aliança na coordenação de interesses em torno do MCMV}

No Governo Lula, a necessidade de ampliação das bases e alianças inaugura uma nova estrutura de relacionamento do governo com a sociedade. Enquanto em governos anteriores o relacionamento Estado-sociedade no setor habitacional esteve estritamente vinculado às articulações do Estado com as coalizões do setor produtivo, no governo Lula, desde sua origem, os movimentos sociais ligados à moradia são trazidos à arena de negociação sem que, ao mesmo tempo, o Estado se furte a estruturar uma relação estreita com o setor empresarial. Cria-se o que se pode chamar de uma triple aliança, ou uma matriz de relacionamento que passa a ter três pontas (Estado, setor empresarial e movimentos sociais), e não mais apenas duas (Estado e setor empresarial) como nos governos anteriores.

As três pontas, no entanto, não são conduzidas na busca de uma agenda comum. Para não contrariar nenhum dos interesses, o governo opta por uma coordenação de interesses com a constituição de duas agendas paralelas, em que cada um dos interesses se vê contemplado (Klintowitz, 2015). A habitação passa a ter duas agendas paralelas para que convivam no governo em uma estratégia de layering (Mahoney, Thelen, 2010), que institui camadas incrementais, tanto sobre os aparatos institucionais herdados dos governos anteriores como em um processo de combinação entre essas duas agendas em disputa.

A persistência do SNHIS ao longo do tempo como o modelo de política habitacional ideal que se busca alcançar e a realpolitik implementada pelo MCMV que utiliza regras que em nada convergem para o modelo idealizado pelo SNHIS, sem contudo eliminá-lo definitivamente, podem ser explicadas pela ideia de decoupling, trazida por Meyer e Rowan (1977), na qual há um respeito "ritualístico" às regras originárias, isto é, apesar de não serem as regras que comandam as instituições, esses "mitos geradores" permanecem como uma espécie de direção moral da política. Assim, o modelo proposto pela plataforma da reforma urbana permanece como o modelo utópico - SNHIS que parece dar a "direção moral" à política, enquanto o modelo que favorece ao setor empresarial - MCMV - é aplicado na prática como a "política real", inviabilizando a possibilidade do SNHIS concretizar-se. Oliveira (2010) identifica esse modelo descrito para a política habitacional, como a prática geral desenvolvida nos governos petistas, denominando esse processo 
de "Hegemonia às Avessas". Segundo o autor, nesse governo constrói-se uma áurea na qual parece que os atores e suas coalizões historicamente dominados passam a comandar a política, pois fornecem a "direção moral" e estão à testa de organizações do Estado e dispõem, ainda, de poderosas bancadas no Congresso Nacional; no entanto, o conjunto de aparências esconde uma nova dominação na qual "não são mais os dominados que consentem em sua própria exploração; são os dominantes - os capitalistas e o capital, explicite-se - que se consentem em ser politicamente conduzidos pelos dominados, com a condição de que a 'direção moral' não questione a forma de exploração capitalista" (Oliveira, 2010, p. 27). A defesa do setor produtivo da indispensável resolução do déficit habitacional explica-se muito bem sob essa abordagem.

Com a dupla agenda instalada, por um lado cria-se uma ilusão para os atores ligados à plataforma da reforma urbana de que um dia se construirá um modelo de planejamento e gestão habitacional descentralizado com autonomia dos governos locais e de provisão por meio de autogestão e, por outro, atende-se aos interesses do segmento produtivo que demanda estabilidade de ganhos. As regras e programas vão se somando e se sobrepondo de forma a agradar todos, sem excluir nenhum interesse do processo.

As duas agendas - da reforma urbana e do setor produtivo -, que caminham paralelamente como se ambas fossem prioritárias para o governo, foram claramente uma das base de sustentação do "lulismo". Singer (2012) denomina "lulismo" a estrutura de arbitragem para presidir um governo de coalizão desenvolvida no Governo Lula. Estruturou-se um modo de governar em que se buscou agradar todos os setores e classes de forma a minimizar os conflitos, radicalizações e mobilizações contrárias ao governo.

No lulismo, pagam-se altos juros aos donos do dinheiro e ao mesmo tempo aumenta-se a transferência de renda para os mais pobres. (...) Enquanto os meios de pagamento crescem, cada fração de classe pode cultivar o seu lulismo de estimação. (...) Por isso o presidente pode pronunciar, para cada uma delas, um discurso aceitável, usando conteúdos diferentes em lugares distintos e, sobretudo, tomando cuidado para que os conflitos não impliquem em radicalização e mobilização. (Singer, 2012, p. 202)

Assim, enquanto o setor produtivo tem importantes ganhos materiais com o MCMV em detrimento da redução do direito à cidade de milhões de famílias de baixa renda, a política habitacional preconizada pelos atores da plataforma da reforma urbana continua persistindo no imaginário e em poucos investimentos institucionais da Secretaria Nacional de Habitação, como parte dos ganhos dos atores ligados à plataforma da reforma urbana. As atas das reuniões do ConCidades mostram esse processo de layering (Mahoney e Thelen, 2010) com clareza. Enquanto o MCMV vai tomando a primazia da política habitacional, na mesma reunião do Conselho se debatem medidas para melhorar esse programa e discutem-se as preocupações sobre o conteúdo dos Planos Locais de Habitação (PLHIS) como se esses ainda fossem relevantes na condução da política habitacional no plano local (Klintowitz, 2015).

Observa-se, portanto, que o próprio layering criado com essa dupla agenda é um importante artifício de manutenção da 
arbitragem que busca contentar todos os atores. 0 layering torna-se mais eficiente, pois as novas sistemáticas esvaziam as anteriores, trazendo amplos benefícios tanto ao Estado como ao mercado privado sem, contudo, trazer o ônus político de desmontar o ideário - o SNHIS - construído a partir da luta de um importante movimento social aliado do governo - o FNRU. Assim, sem que se desmonte os "mitos geradores" (Meyer e Rowan, 1977) constituídos pelas institucionalidades conquistadas pelos ativistas da reforma urbana, volta-se a praticar políticas urbanas e habitacionais semelhantes às realizadas em momentos anteriores da história brasileira, que favorecem outros interesses, sem ajudar, contudo, na implementação da reforma urbana.

Além da manutenção simbólica do SNHIS, a medida mais importante medida para a sustentação da hegemonia dessa política refere-se às alianças estabelecidas e ganhos obtidos pelos movimentos de moradia com o MCMV.

Em um contexto de arbitragem, os empresários do setor produtivo da construção civil e mercado imobiliário que já tinham interlocução estabelecida com o governo, ao entender que o governo petista era conformado por um ambiente de coordenação de interesses em que seriam necessárias a convivência entre as diferentes coalizões, e, se possível, a construção de alianças entre elas, usaram o ConCidades, antes mesmo da ideia da formulação do MCMV, para articular sua interlocução com os movimentos de moradia em busca da criação de laços e alianças, ${ }^{8}$ como parte da estratégia para construir uma ampla coalizão em favor das demandas do setor produtivo, de modo que o governo pudesse implementar seus planos sem mobilizações contrárias da sociedade, como preconizava o lulismo (Singer, 2012).

Por sua vez, os movimentos de moradia, vislumbrando a possibilidade de vinculação de grande volume de recursos para a política habitacional, também quiseram estabelecer uma aliança com os empresários do setor produtivo em torno da PEC da Moradia Digna que precedeu a instalação do MCMV. E demonstrando que a política tem a capacidade de reconfigurar os atores e as coalizões, principalmente quando envolvem importantes recursos capazes de reconfigurar o curso da política pública como um todo (Couto e Abrucio, 2003; Sabatier e Weible, 2007; March, 2010), os movimentos convictos de sua posição no jogo político, compuseram essa aliança apesar dos conflitos ocasionados com os aliados históricos, companheiros de FNRU.

0 governo, por sua vez, ao mesmo tempo que reiterava os laços com os movimentos de moradia nas interlocuções no ConCidades, mas principalmente no atendimento às demandas nos processos de interlocução estabelecidos nos gabinetes, estabelecia novos laços com 0 empresariado do setor, tanto nas arenas públicas criadas, como principalmente nos espaços de gabinetes.

Assim, o ConCidades se constitui, então, como espaço de encontro e articulação entre os vários atores. Mas as negociações eram feitas em outras arenas que eram não públicas, dando mais liberdade e autonomia nas negociações aos atores envolvidos.

No entanto, mesmo com a ampla coalizão formada em torno da PEC da Moradia Digna, sua negociação não foi bem-sucedida; já o núcleo estratégico do governo (Casa Civil, Ministério do Planejamento e Ministério da 
Fazenda) era contra sua aprovação pela crença de que a vinculação do orçamento engessa as possibilidades de ação política do governo. Contudo, em 2008, com a crise internacional adotou-se na prática, no MCMV, o cenário de investimento proposto pela PEC da Moradia Digna, alcançando um investimento aproximado de $2 \%$ do Orçamento Geral da União (OGU) em subsídios habitacionais.

Com os objetivos alcançados, os laços efêmeros entre os empresários da construção civil e movimentos de moradia se afrouxaram (Tarrow, 2009) e cada coalizão passa a cuidar de seu quinhão. Mesmo que de certa forma uma congregação de interesses em torno da manutenção do MCMV permaneça, a atuação destas coalizões demonstra que a aliança entre elas se afroxou pela busca de seus próprios interesses. Como descrito por um empresário do setor da construção civil: "0 sucesso do programa Minha Casa Minha Vida é o fracasso da articulação política do Moradia Digna" (Klintowitz, 2015). No entanto, se por um lado empresários e movimentos passam a não ter mais as mesmas sinergias do momento anterior, por outro, as alianças dessas coalizões com o governo se fortaleceram enquanto o MCMV vigora com extraordinário fonte de benefícios.

Essa aliança se manifesta no ConCidades no qual apenas os conselheiros dos segmentos acadêmicos e profissionais, ONGs e poder público municipal e estadual manifestavam-se com críticas a respeito do descolamento do MCMV com o SNHIS e sobre a necessidade de discussão mais profunda do MCMV nesse conselho, enquanto os representantes de movimentos de moradia e do setor empresarial que já haviam negociado com o Governo anteriormente enxergavam no Programa a concretização de seus interesses (Klintowitz, 2015).

\section{O MCMV e os movimentos de moradia}

Contudo, para os movimentos sociais de moradia, mesmo defendendo o programa adiante da plenária do ConCidades, o percurso do projeto da PEC da Moradia Digna ao Programa MCMV não foi tão direta quanto para o setor produtivo. Assim como o projeto da PEC, que não havia incorporado a proposta da autogestão, ao ser anunciado o MCMV destinava-se apenas para a promoção da moradia por empresas privadas de construção civil. Um fato simbólico que demonstra que inicialmente os movimentos de moradia não estavam contemplados como atores que fariam parte dos beneficiados com o MCMV foi a falta de representação desses movimentos na mesa de lançamento do Programa em 25 de março de 2009. Os movimentos precisaram reivindicar sua participação para serem chamados para o cerimonial.

Contudo, acreditando no apoio do Presidente da República aos seus apelos, os movimentos de moradia solicitaram audiências especiais com o Presidente Lula e com a Ministra Chefe da Casa Civil, Dilma Rousseff, para requerer sua parte no programa. Essas reuniões privadas resultaram positivas e apesar da estrutura do Programa já estar definida nesse momento, foi criada uma nova modalidade especial - o MCMV Entidades - voltada especificamente para promoção de moradia por entidades sem fins lucrativos, incluindo as 
associações e cooperativas habitacionais autogestionárias. Kingdon (2011) argumenta que um bom empreendedor de política pública é capaz de incorporar uma proposta para uma mudança no fluxo na política com a solução de um problema existente que também precisa ser resolvido, articulando assim os problemas, a política pública e política. Assim, Lula, como bom empreendedor de política, aproveitou a oportunidade trazida pelo MCMV para resolver também o problema dos movimentos de moradia, e ganhar a sua chancela para o MCMV.

Utilizando-se da mesma lógica de articulação do setor produtivo que conseguiu estruturar o MCMV em audiências privadas nos ministérios, sem passar pelos foros públicos em que estavam inseridos, os movimentos de moradia também negociaram sua modalidade com o governo em audiências privadas sem passar por arenas públicas. Apesar disso, parte das lideranças, conforme comprovam as atas das reuniões do ConCidades que discutiram o $M C M V,{ }^{9}$ parecia não se preocupar muito com as arenas em que se davam a decisão sobre a política, já que tal programa traria importante benefícios materiais para os movimentos de moradia. Dessa forma, os próprios movimentos sociais de moradia, defensores históricos dos espaços participativos de decisão sobre as políticas urbanas, retiram a negociação da arena pública para a arena privada, conformando-se em não fazer parte do processo decisório das macroestruturas da política habitacional, desde que sejam atendidos por meio de negociação nos gabinetes aos quais conquistaram 0 acesso.

A estratégia de retirada da negociação das arenas públicas para pactuações individuais com cada um dos atores enfraquece os próprios atores que passaram a atuar como cooperantes do governo, ao invés de críticos e formuladores (Gohn, 2010). Contudo, se por um lado os movimentos de moradia continuaram a não participar efetivamente dos processos decisórios da política habitacional e as arenas participativas foram desconsideradas, por outro, fica claro que esse governo não deixou mais de levá-los em consideração na lista de atores contemplados com a distribuição dos benefícios dos investimentos na área, mesmo que de forma assimétrica se comparados aos benefícios obtidos por outros atores. Garantiram-se, assim, recursos para financiar a produção social da moradia realizada de forma organizada, pelos futuros beneficiários e apoio dos movimentos de moradia ao MCMV (Ferreira, 2014; Rodrigues, 2013).

Embora o aporte de recursos na modalidade MCMV-E seja muito reduzido diante do montante global do programa (apenas 2\%) (Rodrigues, 2013), não se pode negar que sua existência foi uma vitória para essa coalizão e que está diretamente relacionada ao fato de que tais movimentos passam a ter um novo status de player no âmbito político (Rolnik, Klintowitz e lacovini, 2014). Esse novo status político trouxe o importante reconhecimento aos movimentos sociais, e não apenas ao setor privado da construção civil, como parceiros do governo no processo de implementação da política de habitação de interesse social (Tatagiba e Texeira, 2014), e, ao mesmo tempo, os reafirmou como apoiadores do governo, e principalmente, do MCMV. Um indicador fundamental da importância dada pelo governo à concertação com os movimentos de moradia foi a criação de uma assessoria da Presidência da Caixa, especialmente para fazer o MCMV-E 
"rodar", e que buscava informar para a máquina, nas palavras do próprio presidente à época da CEF - Jorge Hereda, que as Entidades e sua modalidade MCMV-E eram prioritárias para o governo.

0 MCMV-E passou a ser a principal forma pela qual os movimentos sociais de moradia participam da implementação da política pública (Ferreira, 2014). Em uma pesquisa (Tatagiba e Texeira, 2014), realizada no âmbito da avalição do MCMV-E, todas as lideranças entrevistadas afirmaram de forma categórica o interesse em continuar atuando no MCMV-E, apesar de demonstrarem muita clareza sobre os problemas e limites do programa.

Conquistado em uma lógica estrutural privatista que já estava assentada e que se destinava ao protagonismo da promoção privada da moradia, o MCMV-E surgiu como uma espécie de armadilha perversa. As entidades que desejam produzir com recursos do MCMV-E estão aprisionadas às lógicas do mercado imobiliário privado e precisam disputar terrenos com as grandes construtoras do país. Apesar de parte de os movimentos de moradia que defendem historicamente a produção por autogestão, especialmente a UNMP, estarem tentando utilizar os recursos do MCMV-E para concretizar projetos com esse viés, a inserção da modalidade para os movimentos de moradia em um arcabouço institucional que já estava estruturado para a lógica da produção privada, inviabiliza de muitas maneiras a boa execução do MCMV-E (Rodrigues e Mineiro, 2012).

Nesse esquema que foi criado, mostrou-se mais lucrativo para muitas entidades indicarem beneficiários do que produzir a moradia. Assim, além do ganho de uma pequena parte dos recursos do MCMV para a produção autogestionária, foi significativa a participação dos movimentos na formação das listas de beneficiários das unidades produzidas pela promoção privada no âmbito do MCMV para a faixa 1 em diferentes municípios onde 0 poder público local, responsável pela indicação da demanda, têm reservado um percentual das unidades produzidas para 0 atendimento de famílias indicadas por movimentos sociais. Em muitos municípios do Brasil, a indicação de um percentual de unidades pelos movimentos de moradia passou a se constituir como uma política municipal, ampliando muito os ganhos dos movimentos de moradia com o MCMV. $\mathrm{Na}$ cidade de São Paulo, por exemplo, o Conselho de Habitação decidiu como critério para priorização da demanda que $25 \%$ das unidades serão destinadas a benificiários indicados pelos movimentos de moradia. ${ }^{10}$

É importante destacar que os ganhos de unidades com o MCMV, obtidos pelos movimentos, são importantes para que as lideranças possam atender às suas bases, compostas principalmente por famílias em busca de uma moradia, uma vez que nisso consistirá seu poder de convocação junto a novos integrantes do movimento. Nessa conjuntura, a distribuição de serviços e benefícios sociais passa cada vez mais a ocupar o lugar dos direitos e da cidadania, constrangendo não somente a demanda por direitos, como as próprias arenas públicas construídas para esse fim (Gohn, 2010), já que essa distribuição de benefícios depende apenas da boa vontade e da competência de articulação com os setores envolvidos. Nesse contexto, apesar de os ganhos serem reais, não potencializam mudanças estruturais.

Em governos de esquerda os movimentos sociais tendem a valorizar a maior oferta 
de participação estatal e a disputar nessas instâncias seus projetos e interesses. Contudo, ao mesmo tempo, tendem também a orientar sua ação por uma disposição menos conflituosa e uma postura de maior conciliação, evitando a pressão sobre os governos e diminuindo o uso do protesto como forma de negociação, seja para garantir suas demandas, seja para garantir a governabilidade a partir de uma agenda de esquerda (Dagnino e Tatagiba, 2010). Nesse cenário, a identidade desses movimentos passa a se definir muito mais por sua relação com 0 Estado ou com os partidos do que a partir de sua localização societária (Gohn, 2010) com resultados perversos no que se refere à questão da autonomia. Ao mesmo tempo, ao serem atendido dessa forma, de alguma maneira estão dando uma chancela de qualidade da política, como no caso do Programa MCMV.

É importante considerar que os movimentos de moradia são um tipo peculiar de movimento social. Por um lado, lutam pela mudança das estruturas da sociedade, sendo justamente essa característica que os aliou ao Fórum Nacional de Reforma Urbana (FNRU) na luta pelo direito à cidade. Por outro lado, têm uma base a ser atendida com bens materiais concretos - casas -, sendo justamente o que os levou a estabelecer alianças com os empresários do setor produtivo. Essa dupla característica implica, muitas vezes, escolhas pragmáticas que favorecem alianças que geram ganhos imediatos, mas que podem, ao mesmo tempo, implicar o desvio do caminho que levará à estagnação das mudanças estruturais que defendem. Essas características também os diferencia de outros segmentos que compõem o FNRU - ONGS, setores profissionais e acadêmicos - que não estão submergidos pelo o conflito implícito dos cálculos de trade off entre as mudanças estruturais e 0 atendimento imediato às bases.

\section{A implicações do MCMV para o FNRU}

As diferentes naturezas dos segmentos que compõem o FNRU sempre ocasionarma tensões internas a essa coalizão. No contexto do MCMV, os movimentos de moradia defenderam a existência do MCMV, mesmo que com restrições a algumas de suas normativas, e não quiseram cobrar do Governo mudanças internas ao programa pelos canais institucionais ou em mobilizações públicas muito conflituosas, ao mesmo tempo, os outros segmentos constituintes do FNRU quiseram fazer críticas mais contundentes à estrutura do programa e promover processos de pressão e enfrentamento público (Klintowitz, 2015).

A falta de consenso interno no FNRU fez com que essa articulação tivesse um posicionamento mais discreto em relação ao MCMV. Essa contradição, ao mesmo tempo, favoreceu o Governo que não teve que enfrentar essa oposição, no entanto, fragmentou e enfraqueceu a coalizão da reforma urbana que não conseguiu resolver suas discrepâncias internas. Enquanto esse afastamento ideológico entre os segmentos não pareceu afetar os movimentos de moradia, essa circunstância teve significativa importância para os outros segmentos que, por não terem numerosas bases como os movimentos, ficam enfraquecidos como atores com poder de pressão, mobilização e negociação junto ao Governo. Os movimentos, por sua 
vez, usaram seus canais diretos de articulação para negociar suas demandas particulares, ligadas aos programas, mas não para buscar articulações mais estruturais em torno da plataforma da reforma urbana, o que também fragilizou o FNRU como coalizão e em sua capacidade de advocacy.

Apesar de diminuir os canais de articulação direta e o empenho em busca do apoio ao governo dos segmentos de ONGs e acadêmicos ligados ao FNRU, o Governo não os alijou totalmente do processo de construção da nova política habitacional. Ao elaborar a Medida Provisória (MP 459) que instituiria o MCMV, o presidente Lula concedeu aos defensores da plataforma da reforma urbana um capítulo inteiro sobre a regularização fundiária, sendo responsável por levar à concretização de uma matéria de suma importância para a questão fundiária no Brasil, e que estava em tramitação há muitos anos no Congresso Nacional sem sinais de que teria um desfecho rápido.

0 capítulo sobre regularização fundiária da MP 459/2009 teve sua redação totalmente baseada em um texto que já havia sido produzido na Câmara dos Deputados, no âmbito do processo que discute, desde o ano 2000, a futura Lei de Responsabilidade Territorial Urbana (LRTU) (PL 3 057/2000). 0 texto da MP foi retirado do substitutivo produzido pelo último relator, o Deputado Renato Amary (PMDB-SP) e que estava pronto para a votação em plenário, mas que enfrentava muita oposição. 0 processo já havia passado por três relatores sem sucesso (Silva e Araújo, 2013).

Com esse ato, Lula vislumbrou a possibilidade de contentar - com um programa (MCMV) que a princípio os descontentaria -, os outros atores ligados à reforma urbana, e, também, uma parcela importante do eleitorado que vive em assentamentos irregulares no país. Assim, de forma surpreendente, por não dialogar em nada com o MCMV, a mesma lei que o instituiu foi também responsável por estabelecer uma normatização para a regularização fundiária de assentamentos localizados em áreas urbanas de interesse social, que há muito se tentava, sem sucesso, aprovar no âmbito do Congresso Nacional.

\section{A coordenação federativa do MCMV}

Paralelamente, em um governo que tinha um projeto de manutenção de poder relacionado à articulação federativa, não se poderia desenhar uma política de habitação que não garantisse ganhos para os municípios e para seus prefeitos. Sob o pressuposto de que a promoção habitacional pelos entes locais impedia que os programas "rodassem" no ritmo desejado (Loureiro, Macário e Guerra, 2013; Klintowitz, 2015), mas com o intuito de que os governos locais aderissem à nova política, o modelo do MCMV foi construído delegando aos municípios basicamente o papel de organização da demanda (por meio de cadastros encaminhados à (EF para a seleção dos beneficiários) e, de modo facultativo, à criação de condições para facilitar a produção, mediante a flexibilização da legislação urbanística e edilícia dos municípios e/ou da doação de terrenos. Nesse modelo a necessidade de institucionalidade da gestão é muito pequena, demandando apenas a existência de um cadastro, sendo esse justamente o instrumento mais presente nos 
municípios brasileiros. Em 2009, ano de início do PMCMV, $81 \%$ dos municípios já o tinham (Arretche, 2012).

Indicar a demanda significa, por um lado, um baixo investimento do ponto de vista financeiro e institucional e, por outro, um grande recurso no sentido de angariar possíveis votos em pleitos municipais. A influência dos benefícios eleitorais proporcionados pela inauguração de novos empreendimentos habitacionais, produtos cujo significado vai além das considerações sobre o seu impacto econômico e social, tem um importante potencial para gerar capital político. Os empreendimentos habitacionais construídos no âmbito do MCMV são, assim, "fatos políticos" de dimensão local, regional e nacional, conferindo legitimidade ao exercício do poder por sua elevada visibilidade no conjunto das realizações dos governos (Camargos, 1993). Cada unidade produzida vale para duas contagens, ou seja, o capital político gerado serve tanto para o município quanto para o governo federal (Klintowitz e lacovini, 2014; Rolnik, Klintowitz e lacovini, 2014).

Vendo a possibilidade de ganhos de capital político com o MCMV, muitos governos estaduais também estão querendo "participar da festa". Esses governos têm adicionado recursos aos disponibilizados pelo governo federal para que se consiga implementar empreendimentos nas capitais onde a terra é mais cara e, com isso, têm aproveitado também do capital político gerado pelos empreendimentos produzidos. Assim, um mesmo programa tem unido diferentes esferas de governo, de diferentes partidos, em suas inaugurações.

Se, inicialmente, os governos locais se incomodaram com o formato do Programa que tirava deles o protagonismo, com o passar do tempo perceberam que os benefícios recebidos seriam tantos ou maiores do que se fossem os promotores dos empreendimentos, com a vantagem de que não precisariam despender muitos esforços para isso. Diante desse quadro, é possível afirmar que políticos locais se beneficiam do programa, o que ajuda a entender por que a maioria dos municípios concentrou seus esforços unicamente na viabilização de empreendimentos do MCMV em seu território, deixando de lado seus processos de planejamento ou criação de outras alternativas para solução das necessidades habitacionais (Rolnik, Klintowitz e lacovini, 2014; Polis, 2014). Trata-se de uma postura pragmática, que capta o máximo de benefícios políticos com um mínimo de esforço institucional e financeiro. Nesse contexto, em muitos municípios, como é o caso de São Paulo, foi retirado do orçamento municipal o recurso que antes se destinava à pasta da habitação sob o argumento de que a política habitacional já tinha o recurso proveniente do MCMV (Rolnik, Klintowitz e lacovini, 2014).

Com a estrutura criada inicialmente para o MCMV, os únicos prejudicados seriam os municípios menores, que na MP 459 não estavam contemplados. Originalmente, não parecia fazer sentido expandir a atuação para esses municípios, já que não eram municípios interessantes ao setor produtivo, principalmente na faixa 1, com empreendimentos de grande escala para reduzir custos e ampliar os lucros (Shimbo, 2010). No entanto, ao serem comunicados dos novos rumos da política habitacional, esses municípios menores reivindicaram e negociaram no Congresso Nacional a inclusão de uma modalidade para municípios com menos de 50 mil habitantes. Criou-se, então, uma nova modalidade para o MCMV 
SUB 50 - a oferta pública - conhecida como "SUB-50". Junto com o MCMV-E e o MCMV-Rural, o SUB-50 representa as únicas exceções ao modelo de provisão habitacional com promoção privada.

Nessa modalidade, os munícipios têm um papel mais protagonista sendo responsáveis por acessar o recurso por meio de edital disponibilizado pelo MCidades. No entanto, essas três modalidades são marginais dentro do Programa e representam apenas $11 \%$ do total de unidades previstas. Contudo, mesmo não sendo pensado pelo executivo federal, a inclusão desses municípios menores no bolo do MCMV trouxe importantes apoios públicos da CNM (Confederação Nacional dos Municípios) e Frente Nacional do Prefeitos (FNP) para o governo federal.

\section{Considerações finais}

0 que se percebe ao percorrer este caminho que desvela 0 arranjo institucional de coordenação de interesses em torno do MCMV criada para sustentação desse programa que se transformou na única política habitacional do Brasil por dois mandatos presidenciais é que esse arranjo foi típico do lulismo, em que todos os atores têm seus interesses atendidos, mesmo que de forma assimétrica, e de modo a garantir a continuidade dos ganhos apoiam a política estabelecida e o governo de forma mais ampla.

Enquanto se mantém viva a utopia do caminho preconizado pela plataforma da reforma urbana que alimenta os atores ligados a essa plataforma; cada um dos atores envolvidos no setor habitacional, inclusive esses próprios atores, tem ganhos próprios já que, no contexto geral de formulação do MCMV, foram sendo criadas concertações no próprio programa para beneficiar o maior número de atores possíveis.

Esse modelo de concertação só poderia ser estabelecido em um governo como o de Lula, que já começou com o apoio de uma grande base de movimentos sociais. A inovadora articulação da tríplice aliança que uniu empresários do setor produtivo e movimentos de moradia, opositores históricos, em defesa de uma política, e de seu governo de maneira geral, não seria possível de ser construída em um governo que não chegasse ao poder com a áurea da defesa dos direitos dos excluídos e ao mesmo tempo com o pacto com o empresariado para a garantia do crescimento da economia do país e dos ganhos do capital nacional.

As articulações para a coordenação de interesses em torno da política habitacional aqui demonstrada ocorreram no âmbito das gestões do Presidente Lula. Embora o receituário tenha sido seguido na primeira gestão de Dilma, percebe-se que falta a essa presidente o componente carismático de Lula e a vocação para a coordenação de interesses intrínseca a esse ex-presidente conforme constata Singer (2012): "0 sucesso de soluções intermediárias arbitrais, depende em grande medida, da figura providencial do líder que dá a cada um o seu quinhão" (Singer, 2012, p. 201). 0 que garantiu a estabilidade desta política foi justamente a força da coordenação de interesses que foi articulada de modo a criar um "regime de políticas públicas" (Couto e Abrucio, 2003) quase hegemônico.

No governo Dilma, no entanto, a política e os arranjos institucionais e de atores permaneceram praticamente os mesmos, porém demonstraram esgarçamentos, mesmo antes 
da importante crise política que se deflagrou já no começo de seu segundo mandato. $\mathrm{E}$ como esses arranjos, no setor habitacional e também em outras políticas públicas, foram essenciais para as estratégias para a própria manutenção do poder do governo, seu esgarçamento pode inviabilizar o projeto de manutenção mais à frente.

Outro fato curioso que surge a partir da instalação do regime da política pública do MCMV, é a disputa pelo espaço entre os atores. Os poucos espaços de decisão acerca do MCMV-E, em que se modificam normativas e se disputam recursos, foram ocupados pelos movimentos de moradia ligados ao FNRU, mas com a possibilidade do lançamento da terceira fase do MCMV, assistiu-se a uma clara disputa das novas lideranças de moradia que buscavam brechas para que seus interesses também fossem atendidos de modo que passassem a fazer parte da coordenação de interesses estabelecida.

\section{Danielle Klintowitz}

Instituto Pólis, Urbanismo. São Paulo/SP, Brasil.

daniklin@gmail.com

\section{Notas}

(1) Segundo dirigente da Secretaria Nacional de Habitação, na campanha eleitoral de 2014, as pesquisas apontaram que o programa com maior recall, isto é, o que era mais lembrado pela população quando pensavam nas políticas federais, era o MCMV (Klintowitz, 2015).

(2) O FGTS e o SBPE foram criados e regulamentos em 1966 como para promover o respaldo financeiro necessário à estrutura organizacional do BNH. O FGTS, tendo como fonte de recurso a poupança compulsória de parte dos salários formais captada pelo Governo Federal, é até hoje a principal fonte de recursos de financiamento do desenvolvimento urbano do país com juros mais baixos do que os praticados no mercado. Já no SBPE, cujo os recursos são provenientes das cadernetas de poupança voluntárias é destinado para o financiamento habitacional dos segmentos de mais alta renda com juros menos subsidiados.

(3) É importante notar que, para efeitos metodológicos, este cálculo da focalização do Programa MCMV em relação ao déficit assume que todas as unidades produzidas no âmbito do programa estão atingindo as famílias computadas como déficit e que não há nenhum vazamento. No entanto, sabe-se que parte dos atendimentos não são destinados ao atendimento do déficit calculado pela FJP. Além dos vazamentos pulverizados comuns em programas públicos, parte do atendimento do MCMV está sendo utilizada para permitir o atendimento às famílias que sofreram remoções forçadas para a implementação de novos empreendimentos, como no caso das obras para a Copa do Mundo 2014 e as Olimpíadas 2016. 
(4) O PMCMV, em sua componente urbana, foi operacionalizado para a modalidade da faixa 1 a partir da alocação de recursos orçamentários da União no Fundo de Arrendamento Residencial (FAR) - inicialmente no montante de 14 bilhões de reais - e, em menor grau, ao Fundo de Desenvolvimento Social (FDS) - inicialmente no montante de 500 milhões de reais -, ambos gerenciados pela CEF. O FAR já vinha sendo utilizado na produção de unidades habitacionais para famílias com renda entre três e seis SM, dentro do Programa de Arredamento Residencial (PAR), recebendo recursos transferidos do Orçamento Geral da União (OGU) e do FGTS, e foi utilizado no MCMV para viabilizar a modalidade que passa recursos orçamentários diretamente para as empresas. Já o FDS é um fundo contábil de natureza financeira que funciona com recursos provenientes do Orçamento Geral da União - OGU, com prazo indeterminado de existência, sendo seus recursos destinados para o financiamento de projetos de investimento de interesse social, nas áreas de habitação popular exclusivamente para famílias com renda de até $\mathrm{R} \$ 1600$, por meio da concessão de financiamentos a beneficiários organizados de forma associativa por uma Entidade Organizadora - EO (associações, cooperativas, sindicatos e outros), Organizadora - EO.

(5) O PAC Favelas, voltado à urbanização de assentamentos precários, apesar de não dialogar diretamente com o SNHIS e de passar por fora do FNHIS, é defendido por muitos atores ligados à plataforma da reforma urbana à medida que promove uma atuação mais integrada entre as políticas urbanas (habitação, saneamento, mobilidade) do que a provisão de novas moradias que atua de maneira exclusiva na construção de casas.

(6) Optou-se por realizar este exercício estatístico apenas nos dados de contratação da primeira fase do MCMV, pois os dados do MCMV2, disponibilizados pela CEF, apresentavam muitas inconsistências e não foi possível conseguir uma base mais adequada junto ao gestor do programa até o final desta pesquisa.

(7) A Rede Moradia Cidade foi uma rede nacional de pesquisadores que se reuniram para realizar uma avaliação no âmbito da chamada MCTI/CNPq/MCidades $n^{\circ}$ 11/2012 sobre a inserção urbana dos conjuntos produzidos no âmbito do MCMV em seis estados brasileiros. A rede foi formada por pesquisadores de 11 instituições (universidades federais do Ceará, Pará, Rio Grande do Norte, Minas Gerais, Rio de Janeiro (Ippur e Prourb), universidades estaduais, USP (IAU e FAU), Pontifícia Universidade Católica de São Paulo, Peabiru e Instituto Pólis) que construíram uma metodologia em conjunto para identificação de similaridades e diferenças da implantação desses conjuntos no território nacional. Essa avaliação realizou uma pesquisa com 3.900 famílias com moradias de unidades habitacionais produzidas no âmbito do MCMV, faixa 1, nas diferentes cidades estudadas.

(8) Uma fala de um entrevistado de um conselheiro do ConCidades do setor da construção civil explicita esta estratégia: "Como a distribuição de participação do Conselho [das Cidades], de uma certa forma era um pouco desequilibrada e no fim o governo e os movimentos sociais acabam tendo uma grande maioria, a gente percebeu que a participação nossa [dos empresários] não deveria ser na votação. Não tinha como a gente ganhar a votação, a gente sempre perdia. Mas tinha a discussão, a discussão não é voto, porque na verdade, eu acho que uma coisa que era legal do Conselho é um trabalho de articulação para trabalhar um pouco o consenso, eu acho que era uma cultura, uma coisa que foi bom, era trabalhoso, mas foi bom. Então percebemos que a nossa participação deveria ser na articulação política, na proposta de ideias, na elaboração de algumas propostas que pudéssemos de alguma forma vender as nossas ideias (...) Dessa forma nós conseguimos construir uma parceria com os movimentos sociais, que foi uma coisa muito legal, eu acho que a gente começou no embate com os movimentos 
sociais, a gente tinha visões muito diferentes em algumas coisas, mas conseguimos construir um consenso" (Klintowitz, 2015).

(9) Ata da 20a Reunião do Conselho Nacional das Cidades (MCidades, 2009, s/p).

(10) Valores de imóveis podem inviabilizar projetos habitacionais de São Paulo, Rede Brasil Atual. Disponível em: <http://www.redebrasilatual.com.br/cidadania/2014/02/prestes-maia-estano-grupo-dos-que-201ctalvez201d-nao-valham-a-pena-destinar-para-habitacao-social-afirmasecretario-de-habitacao-4272.html>. Acesso em: 11 fev 2014.

\section{Referências}

ARRETCHE, M. (2012). Capacidades administrativas dos municipios brasileiros para a política habitacional. Brasilia: Brasil, MInistério das Cidades/Cem-Cebrap.

BONDUKI, N. (2014). Os pioneiros da habitação social. São Paulo, Editora Unesp/Edições Sesc.

BRASIL (2014). Balanço PAC 2 - 4 anos de execução. [S.I.]: Ministério do Planejamento.

CAMARGOS, R. (1993). Estado e empreiteiros no Brasil - uma análise setorial. Tese de Doutorado. Campinas, Universidade Estadual de Campinas.

CARDoso, A. L., ARAGÃO, T. A. e ARAUJO, F. D. (2011). Habitação de interesse social: política ou mercado? Reflexos sobre a construção do espaço metropolitano. In: XIV ENCONTRO NACIONAL DA ANPUR. Anais. Rio de Janeiro.

COUTO, C. G. e ABRUCIO, F. (2003). O segundo governo FHC: coalizões, agendas e instituições. Tempo Social, v. 15, n. 2, pp. 269-301.

DAGNINO, E. e TATAGIBA, L. (2010). Mouvements sociaux et participation institutionnelle : répertoires d'action collective et dynamiques culturelles dans la difficile construction de la démocratie brésilienne. Revue Internationale de Politique Comparée, v. 17, n. 2, pp. 167-185.

FERREIRA, R. (2014). Autogestão e habitação: entre a utopia e o mercado. Tese de Doutorado. Rio de Janeiro, Universidade Federal do Rio de Janeiro.

FIX, M. D. (2011). Financeirização e transformações recentes no circuito imobiliário no Brasil. Tese de Doutorado. Campinas, Universidade Estadual de Campinas.

FJP - Fundação João Pinheiro (2004). Déficit habitacional no Brasil. Centro de Estatística e Informações. Belo Horizonte.

(2013). Déficit Habitacional Municipal No Brasil 2010. Centro de Estatística e Informações. Belo Horizonte.

FNHIS (2013). BRASIL, Relatório de Gestão do Conselho Gestor do FNHIS. Ministério das Cidades.

GOHN, M. D. (2010). Movimentos sociais e redes de mobilizações civis no Brasil contemporâneo. Petrópolis, Vozes.

KINGDON, J. W. (2011). Agendas, alternatives, and public policies. Boston, Peasrson. 
KLINTOWITZ, D. C. (2015). Entre a reforma urbana e a reforma imobiliária: a coordenação de interesses na política habitacional brasileira nos anos 2015. Tese de Doutorado. São Paulo, Fundação Getúlio Vargas.

KLINTOWITZ, D. e IACOVINI, R. F. (2014). Political Arrangements of "Minha Casa Minha Vida" Program - The Role of State, Civil Construction Industry and Civil Society. In: XVIII ISA WORLD CONGRESS OF SOCIOLOGY : FACING AN UNEQUAL WORLD: CHALLENGES FOR GLOBAL SOCIOLOGY. Tokyo

KRAUSE, C.; BALBIM, R. e LIMA NETO, V. C. (2013). Minha Casa Minha Vida, nosso crescimento: onde fica a política habitacional? (Texto para Discussão, n. 1.853). Brasília, Ipea,.

LIMA NETO, V. C.; KRAUSE, C. e FURTADO, B. A. (2015). O deficit habitacional intrametropolitano e a localização de empreendimentos do Programa Minha Casa Minha Vida: mensurando Possibilidades de atendimento (Texto para discussão 2044). Brasília, Ipea.

LOUREIRO, M. R.; MACÁRIO, V. e GUERRA, P. (2013). Democracia, arenas decisórias e políticas públicas: o Programa Minha Casa Minha Vida (Texto para Discussão 1886). Brasilia, Ipea.

MAHONEY, J. e THELEN, K. (2010). Explaining institutional change: ambiguity, agency, and power. Nova York, Cambridge University Press.

MARCH, J. G. (2010). Como as decisões realmente acontecem. São Paulo, Leopardo.

MEYER, J. W. e ROWAN, B. (1977). Institutionalized organizations: formal structure as myth and ceremony. American Journal of Sociology, n. 83, pp. 340-363.

OLIVEIRA, F. D.; BRAGA, R. e RIZEK, C. (2010). Hegemonia às avessas: economia, política e cultura na era da servidão financeira. São Paulo, Boitempo.

POLIS, I. (2014). A produção do Programa MCMV na Região Metropolitana da Baixada Santista: impactos urbanos e ambientais dos empreendimentos. São Paulo, MCMV/CNPq.

RIZEK, C. S.; SANTO AMORE, C.; CAMARGO, C. M.; CASTRO, A. Q.; PEREIRA, R. B. e ROdRIGUES, D. P. et al. (2014). A inserção urbana através da produção do MCMV - entidades no Estado de São Paulo: Abordagem etnográfica de casos selecionados. In: III ENCONTRO DA ASSOCIAÇÃO NACIONAL DE PESQUISA E PÓS-GRADUAÇÃO EM ARQUITETURA E URBANISMO. São Paulo.

RODRIGUES, E. L. (2013). Estratégia fundiária dos movimentos populares na produção autogestionária da moradia. Dissertação de Mestrado. São Paulo, Universidade de São Paulo.

RODRIGUES, E. e MINEIRO, E. (2012). "Do crédito solidário ao MCMV entidades: uma história em construção". In: LAGO, L. C. (org.). Autogestão habitacional no Brasil: utopias e contradições. Rio de Janeiro, Letra Capital/Observatório das Metrópoles.

ROLNIK, R.; KLINTOWITZ, D. e IACOVINI, R. F. (2014). Habitação em municípios paulistas: construir políticas ou "rodar" programas? Revista Brasileira de Estudos Urbanos e Regionais, n. 16, pp. 149-165.

SABATIER, P. A. e WEIBLE, C. M. (2007). "The advocacy coalition framework: Innovations and clarifications". In: SABATIER, P. A. Theories of the Policy Process. Boulder, Westview Press.

SHIMBO, L. Z. (2010). Habitação social, habitação de mercado: a confluência entre Estado, empresas construtoras e capital financeiro. Tese de Doutorado. São Carlos, Universidade de São Paulo.

SILVA, R. S. e ARAÚJO, S. M. (2013). Ainda vale a pena legislar: a atuação dos Stakerholders no Congresso Brasileiro. Revista de Sociologia e Política, n. 21, pp. 48-65. 
SINGER, A. (2012). Os sentidos do lulismo: reforma gradual e pacto conservador. São Paulo, Companhia das Letras.

TARROW, S. (2009). O poder em movimento: movimentos sociais e confronto político. Petrópolis, Vozes.

TATAGIBA, L. e TEXEIRA, A. C. (2014). Os efeitos do movimento de moradia sobre as políticas públicas. IX ENCONTRO ABCP. Anais. Brasília.

Texto recebido em 15/out/2015

Texto aprovado em 6/dez/2015 